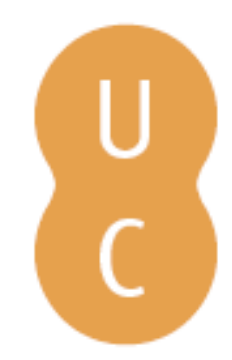

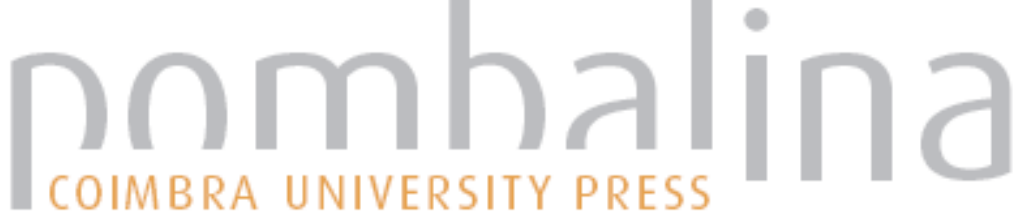

\section{La historiografía latina en el Renacimiento}

Autor(es): Villalba Álvarez, Joaquín

Publicado por: Imprensa da Universidade de Coimbra

URL

persistente: URI:http://hdl.handle.net/10316.2/38952

DOI: $\quad$ DOI:http://dx.doi.org/10.14195/978-989-26-0395-7_6

Accessed : $\quad$ 26-Apr-2023 15:59:57

A navegação consulta e descarregamento dos títulos inseridos nas Bibliotecas Digitais UC Digitalis, UC Pombalina e UC Impactum, pressupõem a aceitação plena e sem reservas dos Termos e Condições de Uso destas Bibliotecas Digitais, disponíveis em https://digitalis.uc.pt/pt-pt/termos.

Conforme exposto nos referidos Termos e Condições de Uso, o descarregamento de títulos de acesso restrito requer uma licença válida de autorização devendo o utilizador aceder ao(s) documento(s) a partir de um endereço de IP da instituição detentora da supramencionada licença.

Ao utilizador é apenas permitido o descarregamento para uso pessoal, pelo que o emprego do(s) título(s) descarregado(s) para outro fim, designadamente comercial, carece de autorização do respetivo autor ou editor da obra.

Na medida em que todas as obras da UC Digitalis se encontram protegidas pelo Código do Direito de Autor e Direitos Conexos e demais legislação aplicável, toda a cópia, parcial ou total, deste documento, nos casos em que é legalmente admitida, deverá conter ou fazer-se acompanhar por este aviso.

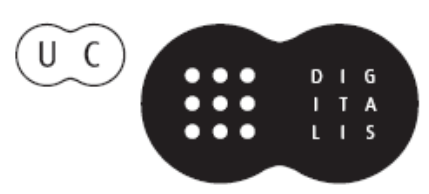


Nair de Nazaré Castro Soares

Santiago López Moreda

Coordenação

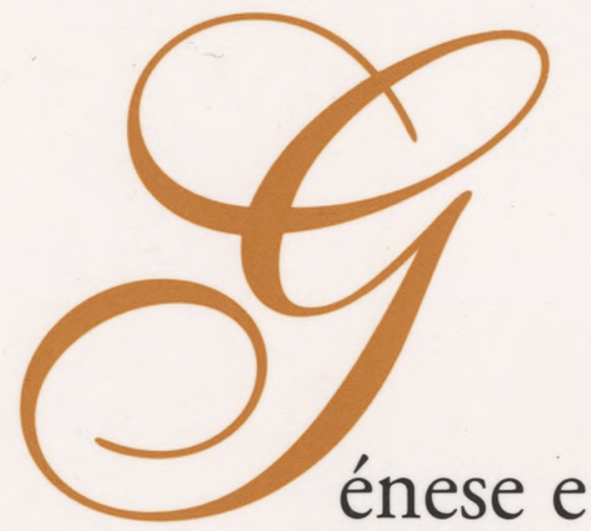

Consolidação da Ideia de Europa

Vol. IV

Idade Média e Renascimento

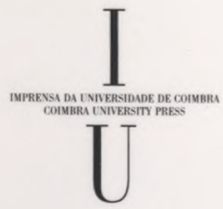

- COIMBra 2009 


\title{
LA HISTORIOGRAFÍA LATINA EN EL RENACIMIENTO.
}

\author{
JOAQUín VILlaLba ÁlVAREZ \\ (Universidad de Extremadura)
}

\begin{abstract}
Dice Garin ${ }^{1}$ que el concepto de Renacimiento ha dividido siempre a los investigadores entre quienes lo consideran un puro retorno a la época clásica y quienes ven en él un verdadero nacimiento, una creación ex nihilo. Y ciertamente debe tener de las dos cosas, si bien siempre ha destacado de este período el advenimiento de la luz y la confianza en el Hombre y su actividad espiritual, frente a la época medieval inmediatamente anterior ${ }^{2}$. No obstante, toda generalización acarrea injusticia, y llamar oscuro al período medieval conlleva la iniquidad de tildar de "tenebrosos" a corrientes tan florecientes como el llamado "Renacimiento carolingio", el resurgimiento humanista del siglo XII o el despertar a la ciencia que se experimenta a partir del siglo XIII, con la asimilación de la cultura árabe por parte de Occidente o la divulgación del aristotelismo que impregna todos los ámbitos del conocimiento humano del momento $^{3}$ : el Renacimiento, más que como reacción, debería sentirse como la consecuencia natural de todo lo anterior, como la asimilación del acervo cultural grecolatino sumado a todo el caudal artístico, espiritual o religioso acumulado durante unos siglos mal llamados "oscuros" pero que dieron como resultado ese despertar humanista al que asistimos en la Italia del Quattrocento. El Renacimiento, en suma, es el resultado de la transformación del mundo medieval en todos los órdenes, incluido el religioso, cuyo símbolo más palpable es

${ }^{1}$ Garin, E., (1986), p. 11.

${ }^{2}$ Parece ser que la expresión "Edad Media" aparece por vez primera en las Historiarum ab inclinatione Romanorum imperii Decades de Flavio Biondo, obra publicada en 1438 aunque escrita unos años antes.

3 "Grandes fueron los pensadores del siglo XII, admirable la figura de Abelardo, exquisitamente "moderno" en su fuerte apasionamiento el romance de Eloísa, poderoso el arte gótico, altísima la civilización urbana, sublime la poesía de Dante, atrevidísima la agudeza crítica del averroísmo latino, profunda la ciencia de los fisicos parisinos y digna anticipadora la obra de Leonardo da Vinci" (E. GARIN, 1986, pp. 11-12).
\end{abstract}


Eneas Silvio Piccolomini, "paganizante desbocado y cristiano austero, cultivador de las humanae litterae e incansable hombre de acción, diplomático habilidosísimo y ardiente cruzado a destiempo" que acabó convirtiéndose en el papa Pío $\mathrm{II}^{4}$.

En el Renacimiento, es la confianza en el espíritu humano y esa nueva relación con la naturaleza y la historia la que da sentido al concepto de "Humanismo" y a expresiones como Humani humaniores facere o la máxima terenciana homo sum: humani nil a me alienum puto ${ }^{5}$, repetidas hasta la saciedad en este tiempo. El Humanismo del Renacimiento es un movimiento cultural que atañe a todos los campos de la actividad intelectual, con una idea irrevocable: el Hombre es el centro de todas las cosas, la criatura más perfecta creada por Dios a su imagen y semejanza. Este hecho es importante, pues por encima de cualquier consideración del Renacimiento como movimiento pagano y racionalista, hay que afirmar su indisoluble dependencia de la religión cristiana: por más que veamos críticas contra la corrupción de la Iglesia, por más que se pretenda ver un paganismo exacerbado en la obra de estos humanistas, este anticlericalismo no es exclusivo del período renacentista ${ }^{6}$ : "se trata de la tradición romanocristiana, que hace suya tanto la herencia de Atenas como la de Jerusalén" ". El Renacimiento, así entendido, supone un cambio de mentalidad literaria y artística, pero también una regeneración intelectual de la civilización cristiana aprovechando el humanismo pagano clásico, de este modo renacido y redescubierto.

El cultivo de la historiografia corre a cargo de estos intelectuales que son los humanistas, transmisores de la tradición literaria latina, en su faceta de profesores, traductores y comentaristas de la misma, pero tambien conocedores de la retórica clásica que tanto influye en la creación literaria, y en su condición de tales son los encargados de escribir obras historiográficas. Un ejemplo elocuente es Lorenzo Valla, autor de una de las cumbres filológicas del Renacimiento - las Linguae Latinae Elegantiae -, que, además de gramático, es un

${ }^{4}$ Cf. F. Socas, "Introducción" a la Descripción de Asia de Eneas Silvio Piccolomini, Madrid, Alianza Ed., 1992, p. XII. Muchas veces se ha advertido este paradójico maridaje intelectual de Piccolomini, que como hombre se llamó Eneas y como papa Pío, justamente el epíteto del héroe troyano.

${ }^{5}$ TERENCIO, Heautontimoroumenos, 77.

${ }^{6}$ Baste recordar la crítica de la corrupción eclesiástica en los poemas goliardescos medievales, con los Carmina Burana a la cabeza, o algún episodio del Libro de Buen Amor, de nuestro Arcipreste de Hita.

${ }^{7}$ E. GARIN (1986), p. 23, afirma que a partir de autores como Cola di Rienzo, Petrarca o Colluccio Salutati "se hace muy raro encontrar una comprensión de lo antiguo separada de una religiosidad profunda". 
gran conocedor de la tradición clásica en materia de historiografia, comentarista de Livio, traductor de Salustio e historiadores griegos como Tucídides o Heródoto y autor de la Historia de Fernando de Aragón, que compone para mayor gloria de Fernando de Antequera, padre de su protector, Alfonso el Magnánimo, rey de Nápoles ${ }^{8}$.

El hecho de escribir, todavía en los ss. XV y XVI, obras históricas en latín, nos lleva a hacernos una pregunta: ¿qué sentido tiene seguir escribiendo en una lengua que ya no se siente como materna, toda vez que las lenguas vernáculas comienzan a disponer de una literatura propia, e incluso formas literarias como el romance se han introducido en la historia? Durante el Renacimiento, el latín sigue siendo la lengua de cultura, la lingua franca, el vehículo universal e ideal de expresión para esa sociedad supranacional y cosmopolita que traspasa fronteras y que constituyen los hombres de letras, conocidos como "humanistas". Además, la riqueza y la profundidad conceptual de la lengua latina y su amplia tradición literaria de siglos la prestigiaban ante las lenguas nacionales?

Por otra parte, asistimos en este momento concreto de la historia a un indiscutible impulso de renovación estética, un acentuado respeto y fidelidad a los clásicos y un profundo rechazo del latín de los escolásticos. Así pues, los principios que mueven la historiografia neolatina renacentista se reducen, básicamente, a dos, relacionados entre sí: a) su dependencia de la historiografía grecolatina, sobre la que se asienta tanto formal como metodológicamente, y b) su ruptura con formas medievales y "eclesiásticas", al entender que la historia debe desprenderse del Providencialismo y que es el propio hombre el protagonista de los hechos. Esta reivindicación del mundo clásico afecta necesariamente a la historiografia, género literario que, como en la Antigüedad, destaca por su utilidad para la sociedad y las clases dirigentes: la historia escrita en latín en esta época aspira a difundir unos hechos de este modo perpetuados para mayor gloria del rey, familia o nación objeto de alabanza en cada caso. A ello habría que sumar, también, la concepción de la historia como testimonio de la experiencia humana, un sentimiento fuertemente humanista que impregna estos siglos, y de los que la historiografia no es más que uno de los vehículos más naturales y frecuentes de expresión, tal vez el mayor.

El florecimiento de la historiografia en los siglos XV y XVI toma cuerpo bajo diferentes formas: ediciones de obras clásicas (muchas recién descubier-

${ }^{8}$ De hecho, no pocos especialistas señalan la Historia de Fernando de Aragón como antesala para una ulterior biografia del propio Alfonso.

${ }^{9}$ No en vano, en estos siglos las diferentes lenguas vernáculas siguieron beneficiándose de esa riqueza, por la via de la implantación de cultismos y otras expresiones equivalentes. 
tas, con el consiguiente interés por su rápida divulgación internacional); traducciones de estas mismas obras al vernáculo y también al latín ${ }^{10}$; elaboración de romances y cantares que narran, en lengua vulgar, las hazañas de los nuevos héroes nacionales; o la elaboración de obras históricas, originales en latín, fuertemente influenciadas por la retórica, desde Cicerón.

En consonancia con ello, los estudiosos de la materia ${ }^{11}$ atribuyen tres objetivos fundamentales para la abundante producción historiográfica neolatina de estos siglos:

1) la naturaleza eminentemente literaria de la historia, una consecuencia más de su condición de opus oratorium maxime;

2) su pragmatismo en el plano político y moral, como prontuario de ejemplos antiguos sumamente útiles para los gobernantes (Valerio Máximo y Plutarco son referentes obligados);

y 3) una finalidad marcadamente propagandística y patriótica, normal en una época en que comienzan a emerger sentimientos nacionalistas y luchas dinásticas y religiosas.

\section{LA HISTORIA COMO LITERATURA.}

Desde Cicerón se siente la historia como género literario que exige un tratamiento retórico y estético: con ello no se trata de tergiversar o encubrir el principio inalienable de la veritas - aunque muchas veces así sea -, sino de presentar los hechos de una forma adecuada, con un estilo que haga agradable

${ }^{10}$ Es el caso de las obras escritas en griego. Así, por ejemplo, en el ámbito del humanismo italiano, la traducción latina de Tucídides o Heródoto por parte de Lorenzo Valla, las de Polibio o Plutarco de la mano de otros gramáticos renacentistas como Perotto o Guarino, la de Jenofonte de Leonardo Bruni, etc. Otra práctica cada vez más corriente es la de verter a la lengua del Lacio obras escritas en vernáculo, como señalamos más abajo a propósito de Nebrija en España.

"A modo de muestra citaremos a Ferguson (1969), pp. 17 ss., TATE (1970), passim, Cotroneo (1971) o Hinojo (1994), pp. 34 ss. Además de estas tres características fundamentales, algunos estudiosos aducen otras, como es el caso de FUETER (1953), que señala las siguientes: a) El interés lexicográfico, a la hora de acunar nuevos términos para las nuevas realidades: los historiadores renacentistas serán partidarios de emplear vocablos clásicos para estas nuevas realidades, en lugar de emplear la correspondiente palabra moderna o vulgar, en aras de ser más respetuoso si cabe con la pureza del latín clásico; b) en consonancia con la característica anterior, se procede a la imitación de los historiadores clásicos, de las técnicas y recursos historiográficos como la descripción de batallas, las arengas, los discursos, las digresiones o los retratos, un elemento diferenciador frente a la historiografia medieval; y c) el carácter laico de la historia, sin menoscabo por ello de la religiosidad de los historiadores: a veces se da más importancia a conceptos de clara raigambre clásica como la Fortuna, en lugar de recurrir a la Providencia como impulsor de los hechos históricos. 
la lectura. La consecución de la eloquentia ${ }^{12}$ es la meta que debe perseguir cualquier ciencia o arte, y la historia no va a ser una excepción, menos en una época en que desde todos los campos del saber se reclama la necesidad de escribir latín correctamente, esto es, como lo hacían los modelos de la Antigüedad. Unos ejemplos: Giovanni Antonio Viperano pondera la dificultad de la labor del historiador, al más puro estilo de Salustio en Bellum Catilinarium, y pasa a enumerar las cualidades que debe atesorar un buen historiador:

Nec quisquam putet facile esse scribere historiam, nam praeter oratoriam facultatem, cuius est simpliciter, breviter et aperte res gestas exponere, prudens et grave iudicium, syncerus et integer animus, liberalium et optimarum artium cognitio, plurimarum et maximarum rerum peritia requiritur, ut ex hoc libello disces, in quo scribendae historiae rationem tradimus, quam in excellentium historicorum monumentis notavimus (VIPERANO, De scribenda historia, p. 165) ${ }^{13}$.

Valla considera la oratoria como la madre de la historia ${ }^{14}$, y evoca las palabras de Cicerón, cuando propugna que el historiador sea un exornator rerum y no un simple narrator, o que la historia es tarea de los oradores. De hecho, así piensan otros teóricos de la historia, como Jorge de Trebisonda, cuyos Rhetoricorum libri $V$ deben mucho a las reflexiones ciceronianas del De oratore.

Para los hombres de letras del Renacimiento, el historiador precisa unas cualidades intelectuales innatas y unos conocimientos teóricos y actitudes que brinda la retórica. Sólo la formación retórica faculta al historiador para expresarse correctamente (eloquentia), a la manera de un "orador que escribe", al tiempo que le ofrece un sinfin de ejemplos sacados de la Antigüedad, de los que el historiador debe echar mano, mediante el proceso de la imitatio, a la hora de componer su propia obra. Así se explica la inserción - en las historias neolatinas - de discursos, digresiones, proemios o retratos que denotan el aprendizaje retórico al servicio de la historia, amén de otros procedimientos como

${ }^{12}$ Las alusiones a la eloquentia como instrumento que debe guiar a los historiadores aparecen por doquier: regina rerum et perfecta sapientia la llama Valla, parafraseando una expresión de Eurípides (Elegantiae, proem. al libro IV, ed. S. López Moreda, Cáceres, 1999, p. 410); de ella dice Petrarca Opus ipsa mole mirabile stupendumque... ut ab arce eloquentiae non multum abesse videatur (Rerum memorandorum libri, ed. Billanovich, Florencia, 1937, I, 18); Salutati afirma que la elocuencia cunctas alias scientias, sive speculative sive practice sint, omnes vite nostre partes exornat, colit celebratque (Epist. 3.411).

${ }^{13} \mathrm{El}$ mismo autor, unas páginas más adelante, señala que el historiador está obligado a narrar los hechos clara y sabiamente: Ut gestae res sunt bene, hoc est, syncere, dilucide et sapienter narrare, hoc est proprium historici munus (168a).

${ }^{14}$ Oratoriae artis, quae historiae mater est (L. VAlLA, Gesta, proem. 1). 
la varietas, que mantiene atento al lector; la auxesis, la alteración de los hechos reales en aras de un mayor dramatismo; o la constante recreación de ambientes clásicos, por medio de citas de autores erigidos en modelos ${ }^{15}$. Todo lo que supone reflejar y retratar el entorno literario clásico, del que los humanistas se consideran continuadores naturales ${ }^{16}$, es una consecuencia más de por qué la historia durante el Renacimiento será redactada en lengua latina, y no sólo en vernáculo.

Que una obra histórica sea tarea de oradores no es sólo preocuparse de la elocutio, también ha de tener en cuenta la inventio o la dispositio: a la selección de material hay que unir la adecuada y juiciosa concatenación de consilia, acta y eventus, al tiempo que un correcto uso de la lengua latina, lo que se consigue por medio de la imitación de los modelos clásicos del género: Cicerón, en la parte doctrinal; Livio, en la plasmación de dicha doctrina. En suma, la historia contribuye a deleitar al lector a la vez que instruirle, sin menoscabo de la verdad.

La elección de la lengua del Lacio para la composición de la historia resulta lógica, pues a partir de Valla se difundió la idea de que la eloquentia va unida irremediablemente al latín ${ }^{17}$, una lengua que disponía de una tradición literaria y una riqueza expresiva de la que carecían las lenguas nacionales: la historia así concebida resulta amena de leer, en su condición de heredera del arte de composición clásico en el que predomina la delectatio connatural al hecho literario. Y de paso, la transmisión por toda la Europa culta de cualquier obra escrita en esa lengua era mucho mayor, lo que casa muy bien con otro de los rasgos de la historiografia neolatina renacentista, como es su tendencia propagandística.

\section{LA HISTORIA COMO EJEMPLO.}

El utilidad de la historiografia, que tan bien resume la expresión ciceroniana historia magistra vitae, sigue siendo, en el Renacimiento, uno de los distintivos del género ${ }^{18}$ : la historia adquiere un significativo calado tanto ético como político, "en tanto en cuanto el príncipe, el destinatario de estas obras, deberá sacar consecuencias oportunas a través del conocimiento y observación

${ }^{15}$ Esto lleva a Fontán a considerar el método de los historiadores latinos del Renacimiento como un mosaico en el que se encajan, a la manera de las piezas, toda la fraseología, los ejemplos y las referencias de sus antecesores romanos. Cf. A. FONTÁN (1974), p. 267.

${ }^{16}$ Incluso se llega a justificar, en un tono nacionalista recalcitrante, la necesidad de que sean los italianos los encargados de escribir historia, como descendientes directos y legítimos de aquellos otros romanos que les sirven de modelo. Así procede Valla en su proemio a las Elegantiae (ed. S. López Moreda, Cáceres, 1999, vol. I, pp. 56 ss).

${ }^{17}$ El corolario de este pensamiento puede ser la expresión "lo que no se puede decir en un buen latín, no merece la pena ser dicho".

${ }^{18}$ Cf. la utilísima selección de textos sobre esta cuestión, en E. GARIN (1986), pp. 133 ss. 
de situaciones análogas del pasado, en orden a la custodia del bien común",19. Ya en los albores mismos del Renacimiento, Petrarca resalta el valor paradigmático de la historia, como manual de conducta ideal para los que la lean:

Hic enim, nisi fallor, fructuosus historicorum finis est: illa prosequi quae vel sectanda legentibus vel fugienda sunt (PETRARCA, De viris, proem.).

Por lo demás, la razón primera de la historia es salvar del olvido el mayor número posible de hechos, por dos causas principales: o bien por pura erudición, simple alarde docto de una clase intelectual (tarea de los llamados "anticuarios"); o para la enseñanza concreta a los políticos y, en general, a la sociedad del futuro ${ }^{20}$. La historiografia antigua surte de exempla a los hombres del Renacimiento, y se erige en la herramienta idónea para respaldar los nuevos modelos ideológicos y políticos de la Europa renacentista; de hecho, se incide sobre la conveniencia de que los príncipes tengan conocimientos de historia tanto griega como romana, lo que les ha de aprovechar en el desempeño del poder, en la medida en que será un buen gobernante aquél que imite las acciones virtuosas del pasado y desprecie las inmorales. Es una consecuencia más del compromiso que el individuo del Renacimiento ha contraído con la comunidad, de su firme y activa participación en la vida civil, de su apología de los valores del Estado y, en general, de la valoración del Hombre como motor de la sociedad: es lo que recibe el nombre de "Humanismo cívico", un "movimiento literario y educacional de reforma dirigido a las clases políticas de las ciudades-estado italianas" ${ }^{21}$. En efecto, el valor doctrinal del exemplum queda patente por la vigencia que siguen teniendo los Hechos y dichos memorables de Valerio Máximo, reeditado hasta la saciedad en estos siglos, así como la aparición de otras colecciones de ejemplos, como los Rerum memorandorum libri de Petrarca, los De memorabilibus factis dictisque exemplorum libri $X$ de Sabélico, los Dictorum factorumque memorabilium libri VI de Marco Marulo o la De dictis factisque memorabilibus collectanea de Bautista Fulfoso ${ }^{22}$.

${ }^{19}$ B. CuART Moner (1994), p. 45.

${ }^{20}$ L. Marineo Sículo destaca, en el segundo de los prólogos de su De rebus Hispaniae memorabilibus (ed. de Rivera Martín, p. 18), que las enseñanzas de la historia no deben reducirse a los soberanos, sino ampliarse a los generales y los soldados, a los gobernadores de las provincias, a los magistrados de las ciudades, a los jefes del estado e incluso a los grandes comerciantes.

${ }^{21}$ Son palabras de HANKINS, en su "Introducción" a las Historiae Florentini populi de Leonardo Bruni, p. IX.

${ }^{22}$ Sobre la pervivencia de Valerio Máximo desde la Antigüedad hasta nuestros días, cf. nuestra "Introducción" a Valerio Máximo, Hechos y dichos memorables (intr., trad. y notas de S. López Moreda, Mª L. Harto Trujillo y J. Villalba Álvarez), Madrid, Gredos, 
Lógicamente, esta finalidad didáctica, unida a su tendencia propagandística, como diremos más adelante, obliga a una selección de aquellos hechos adecuados y favorables a lo que se quiere narrar con la consiguiente omisión de los que no lo son, lo que redunda en un menoscabo de la objetividad y una conculcación de la prima lex historiae, la veritas. En Lorenzo Valla llama la atención la supremacía de los exempla de la historia sobre los preceptos de los filósofos ${ }^{23}$. Ello significa que, en el Renacimiento, se defiende la historia por encima de otras actividades intelectuales como la poesía o la filosofia, invirtiendo así la jerarquía de géneros establecida en época medieval, que confería la preponderancia de la filosofia sobre el resto. En el proemio a su Historia de Fernando de Aragón, Valla afirma:

Historicum vero tantum narrare qualis unus quispiam aut alter fuerit, veluti Thucydides, qui gesta Periclis, Lysandri aliorumque nonnullorum sui temporis scribit. Ita primas partes tribuunt philosophis, secundas poetis, tertias postremasque historicis. Ego vero, cum huic nequaquam opinioni assentiar, tamen poetis multo plus quam illi faciunt tribuo adeo ut eos aut comparem philosophis aut anteponam, sed non continuo historicis preferam ac ne fortasse quidem conferam. Decet enim opus quod aggrederis libero ore defendere (VALLA, Gesta, proem. 1-2).

La importancia del pasado y sus beneficios para el futuro propician la investigación de la antigüedad griega y romana, tanto de los propios hechos históricos como de otros datos de índole geográfica, etnográfica, arqueológica o topográfica. De ahí la aparición de obras de carácter conjuntamente histórico, arqueológico y geográfico, como la Italia illustrata o la Roma instaurata, de Flavio Biondo ${ }^{24}$, que llevan a Joan Margarit a decir, al principio de su Paralipomenon:

Quis enim futuram agere vitam excogitat, qui diem suae nativitatis ignorat, aut quis quo tendat scire potest, qui unde venit nesciat?"(MARGARIT, Paralipomenon, fol. 1r.).

2003, p. 55-71. Sobre la proliferación de las colecciones de exempla durante el Renacimiento, cf. J. ARAGÜÉS AldAZ (1993), pp. 267 ss., de quien tomamos la referencia de los manuales.

${ }^{23}$ Ya antes de Valla había esbozado esta misma idea Colluccio Salutati, célebre secretario florentino de finales del s. XIV, discípulo de Petrarca: Itaque nisi nobilia philosophorum praecepta historicorum oratio comprobaret, inanes illae chartae, ridiculae sententiae, commenticia futilisque doctrina viderentur (C. SALUTATI, Epist. 2. p. 295)

${ }_{24}$ R. B. TATE (1970), p. 140, considera este tipo de obras como "una especie de geografia histórica, en la que el pasado se proyecta en perspectiva desde el presente por la identificación de nombres antiguos y modernos". En esta linea cabe incluir también algunas obras de Eneas Silvio Piccolomini como su Europa sui temporis varias continens historias (1458), el De Asia (1461), o los tratados de antiquitatibus, como el de André de Resende, todos ellos participes de un anhelo enciclopedista por el conocimiento profundo de lugares y su historia. 
Los historiadores renacentistas contaban con la perspectiva suficiente que les otorgaba el paso del tiempo para valorar en su justa medida la importancia de la historia desde el punto de vista político, y reivindican su labor, tanto o más importante que la del propio protagonista de los hechos. Lo había dicho Salustio en su Conjuración de Catilina y en la Guerra de Yugurta ${ }^{25}$, y lo siguen diciendo, more Sallustiano, todos aquellos que pretenden dignificar su condición de transmisores de unos hechos gracias a ellos inmortalizados, unos hechos, por otra parte, tanto o más dignos de recuerdo que los antiguos. En este sentido hay que entender las palabras de Poggio Bracciolini ${ }^{26}$, para quien Livio, Virgilio y Horacio hicieron grande a Roma, como Homero, Heródoto o Tucídides a Grecia; en la Edad Media no faltaron grandes hombres, sino grandes escritores.

Esta idea del "literato dispensador de gloria", como la llama Garin ${ }^{27}$, expresa sin más el aforismo latino verba volant, scripta manent, que sirve en este caso para reivindicar la composición de obras históricas como ejemplo útil para el futuro y que estimula la aparición del mecenazgo. Valla, en el Prefacio a sus Elegantiae, antepone el culto a las letras a las acciones valerosas de los hombres: éstos son verdaderamente hombres majestuosos por aumentar la grandeza del pueblo romano, pero aquéllos son calificados de divinos, por educar al individuo, enseñar las leyes y ayudar, en fin, a la salvación del mundo ${ }^{28}$.

Con el objeto de silenciar defectos indeseables, la verdad histórica puede disfrazarse: lo que prima en cualquier historia es su utilitas para los gobernantes. Se opta por una selección parcial de los hechos, no por falsear la realidad; así no se quebranta la lex veritatis. Nebrija pondera la importancia del exemplum y, evocando a Horacio, compara la historia con la pintura, pues también sirve

${ }^{25}$ Pulchrum est bene facere rei publicae, etiam bene dicere haud absurdum est; vel pace vel bello clarum fieri licet; et qui fecere et qui facta aliorum scripsere, multi laudantur. ac mihi quidem, tametsi haudquaquam par gloria sequitur scriptorem et auctorem rerum, tamen in primis arduom videtur res gestas scribere: primum quod facta dictis exequenda sunt; dein quia plerique quae delicta reprehenderis malevolentia et invidia dicta putant, ubi de magna virtute atque gloria bonorum memores, quae sibi quisque facilia factu putat, aequo animo accipit, supra ea veluti ficta pro falsis ducit (SALuSTio, Cat. 3); Atque ego credo fore qui, quia decrevi procul a re publica aetatem agere, tanto tamque utili labori meo nomen inertiae inponant (SALUSTIO, Iug., 4.3).

${ }^{26}$ Poggio, Epist. V.6.

${ }^{27}$ E. GARIN (1986), p. 59.

${ }^{28}$ L. VAlla, prefacio a Elegantiae (ed. S. López Moreda, Cáceres, 1999, pp. 56 ss): Quare quis aequus rerum aestimator non eos praeferat, qui sacra litterarum colentes, iis, qui bella horrida gerentes, clari fuerunt? 
para exaltar lo bello y silenciar lo desagradable; en otras palabras, la verdad puede ceder ante la ejemplaridad:

Erit itaque historia tanquam pictura, pulchra extollet, turpia, si tolerabilia sunt, dissimulabit, si latere non possunt, mitiori vocabulo nominabit (NEBRIJA, Divinatio, p. 130$)^{29}$.

Un rival de Nebrija como es Marineo Sículo va un poco más allá y afirma que la pintura es inferior a la historia; mientras aquella sólo muestra la superficie, en ésta se puede profundizar en lo interior. El ejemplo que aduce es diáfano: por más que Apeles retratase a Alejandro Magno, conocemos su figura gracias a Clitarco, Curcio Rufo o Arriano:

Haud enim Alexander Macedonum rex nobis cognitus esset, quamvis ab Apelle celeberrimo sui temporis pictore diligenter pingi se curaverit, nisi res ab eo fortissime gestas, vel graece Clitarchus aliique Graecorum plures, vel Curtius et Arrianus latine conscripsissent (MARINEO, De rebus, p. 20).

Esta asociación entre historia y pintura como forma de resaltar la utilitas del género histórico es un tópico arraigado en la Antigüedad: Salustio o Livio aluden en sus proemios a la pintura para evocar la imaginería de hombres ilustres por sus virtudes ${ }^{30}$. Por lo demás, es la ejemplaridad (cf. el aforismo exempla fidem faciunt $^{31}$ ) la que convierte a la historiografia del Renacimiento

${ }^{29} \mathrm{Ya}$ antes que el Lebrisense, Eneas Silvio Piccolomini (Epist. CXIX, Opera, Basilea, 1571 , p. 646) ensalza la similitud entre la elocuencia y la pintura, y en este sentido cabe recordar nuevamente el componente retórico de la historia: "La elocuencia y la pintura se aman entre sí. La pintura requiere ingenio y la elocuencia exige un ingenio nada vulgar, sino profundo y grandísimo. Es extraordinario observar de qué manera sucede que, allí donde florece la elocuencia, florece también la pintura, como nos lo enseñan los tiempos de Demóstenes y de Cicerón (...). Después de Petrarca resurgieron las letras, después de Giotto volvieron a adquirir valor las manos de los pintores, $\mathrm{y}$ ahora vemos a esas dos partes juntas en grado máximo" [traducción tomada de E. GARIN (1986), p. 64].

${ }^{30}$ Nam saepe ego audivi $Q$. Maxumum, P. Scipionem, praeterea civitatis nostrae praeclaros viros solitos ita dicere, quom maiorum imagines intuerentur, vehementissume sibi animum ad virtutem adcendi. Scilicet non ceram illam neque figuram tantam vim in sese habere, sed memoria rerum gestarum eam flammam egregiis viris in pectore crescere neque prius sedari, quam virtus eorum famam atque gloriam adaequaverit (SALUSTIO, Iug., 4.5-6); Hoc illud est praecipue in cognitione rerum salubre ac frugiferum: omnis te exempli documenta in inlustri posita monumento intueri (LIVIO, AVC, 1. pr.10).

${ }^{31} \mathrm{Cf}$. Quintiliano, Inst., 10.2.1 ss: Ex his caeterisque lectione dignis auctoribus et uerborum sumenda copia est et uarietas figurarum et componendi ratio, tum ad exemplum uirtutum omnium mens derigenda. Neque enim dubitari potest quin artis pars magna contineatur imitatione. Nam ut inuenire primum fuit estque praecipuum, sic ea quae bene 
en vademécum al servicio de los gobernantes, un doctrinario de ejemplos que ayude a los príncipes a seguir el camino de la virtus y desechar las acciones indignas. La antitesis virtus/vitium aparece por doquier, representada en los protagonistas de la historja como verdaderos motores del relato histórico. Ronda en este tiempo una idea moderna y, al mismo tiempo, de clara raigambre clásica: si son las acciones individuales las que conforman la historia, el aprendizaje de ésta será necesario para que el ciudadano alcance la virtud por la vía de la experiencia del pasado. Y es que, como ha apuntado la Dra. Castro Soares ${ }^{32}$, la reorganización política de la vieja Europa fue proclive a la recepción de modelos antiguos de la historiografia y a la subsiguiente aparición de tratados teóricos sobre doctrina política. En este sentido,. "la producción histórica de la Antigüedad grecorromana, a partir del siglo XIV, desempeña un papel significativo en la consolidación del concepto de estado y en la definición de los derechos y deberes de gobernantes y gobernados, dentro de una cosmovisión, donde la moral tiene su poder ${ }^{\prime 33}$. No es casual que en esta época surjan obras sobre la figura del princeps como dominador del Estado: el De monarchia de Dante (c. 1314), el Momus de León Batista Alberti (c. 1443), el De liberorum educatione (1450) o el De educatione puerorum ad regem Bohemiae Ladislaum (c. 1470) de Eneas Piccolomini, el De optimo cive de Platina (1481), El principe de Maquiavelo (1513) o, ya en vernáculo, los tratados de Guicciardini ${ }^{34}$ se inscriben en esta corriente de manuales de conducta para príncipes, que rezuman tradición clásica y hunden sus raíces en la historiografia grecolatina, más concretamente en la vertiente filosófica de Polibio, Tácito o Salustio, para conformar una teoría política que sirva de provecho a los gobernantes. La historia del Renacimiento "está poblada por esas figuras geniales sobre las cuales las figuras de la antigüedad, exaltadas por los humanistas, ejercen una poderosa fascinación" ${ }^{35}$. Aníbal, César, Escipión o Alejandro Magno se convierten en ejemplo - que seguir o eludir, según el caso -

inuenta sunt utile sequi. Atque omnis uitae ratio sic constat, ut quae probamus in aliis facere ipsi uelimus. Sic litterarum ductus, ut scribendi fiat usus, pueri secuntur, sic musici uocem docentium, pictores opera priorum, rustici probatam experimento culturam in exemplum intuentur, omnis denique disciplinae initia ad propositum sibi praescriptum formari uidemus.

${ }^{32}$ N. N. CASTRO SOARES (2002), p. 18.

${ }^{33}$ N. N. CASTRO SOARES (2002), p. 36.

${ }^{34}$ A la pluma de Guicciardini debemos obras tan significativas como las Considerazioni intorno ai Discorsi del Machiavelli sopra la Prima Deca di Tito Livio, Del modo di ordinare il governo popolare o el Dialogo del reggimento di Firenze, entre otras.

${ }^{35}$ E. Garin (1986), p. 160. 
para los gobernantes del Quattrocento, y ejercen una poderosa influencia en su concepción del poder.

Pero hay más: a la obra de estos "analistas políticos" hay que sumar sobre todo a mediados del siglo XVI - otras obras también teóricas sobre el género historiográfico. Como en otras disciplinas ${ }^{36}$, proliferan tratados de scribenda historia como el ya citado de Viperano y otros por el estilo ${ }^{37}$, en los que se plasman de forma conjunta las ideas dispersas de preceptistas antiguos como Aristóteles, Cicerón o Quintiliano.

Así pues, la historiografía grecolatina proporcionó temas y formas, el uso conveniente de las fuentes y, en suma, una estética acorde a la grandeza de los hechos narrados ${ }^{38}$. En este ambiente nace la historiografia renacentista, una de cuyas consecuencias es la separación entre historia universal e historia regional: el aretino Bruni escribe la historia de Florencia sin tener en cuenta nada más, todo lo contrario que los cronistas medievales, para los que "su país no era más que una parte de la Cristiandad" ${ }^{39}$.

${ }^{36}$ Sirvan de ejemplo los tratados de conscribendis epistolis, que se venían incluyendo habitualmente en las gramáticas latinas desde la Antigüedad tardia, que siguieron componiéndose durante el período medieval bajo la denominación de artes dictaminis y que llegan al Renacimiento de la mano de humanistas tan insignes como Erasmo o Vives, quienes realzaron la importancia de la epistolografia como género literario en el que la retórica desempeña un papel significativo.

${ }^{37}$ Sirvan de ejemplo obras como el diálogo Actius de Juan Joviano Pontano (1499), De facultate historica disputatio (1548) de Francesco Robortello, De scribenda universitatis rerum historia (1551) de Cristoforo Mileo, De historiae institutione liber (1557) del español Sebastián Fox Morcillo, De institutione historiae (1561) de François Bauduin, De conscribenda historia de Ventura Cecco (1563), Methodus ad facilem historiarum cognitionem (1566) de Jean Bodin. A estos hay que sumar otros escritos en lengua vernácula, como los Dialoghi dell'Historia (1542) de Sperone Speroni, el Ragionamento della eccellentia et perfettione della historia (1559) de Dionigi Atanagi o el Della historia diece dialoghi (1560) de Francesco Patrizi. También abordan la historia desde su condición de opus oratorium tratados de retórica como los Rhetoricorum libri $V$ de Jorge de Trebisonda (Alcalá, 1511) y algunas consideraciones sueltas en obras igualmente retóricas como las del español Luis Vives.

${ }^{38}$ En su excelente trabajo sobre las crónicas hispanas de época visigoda, GALÁN SÁNCHEZ (1994, pp.15 ss.) señala las cuatro características principales que definen la crónica como subgénero historiográfico y que chocan de frente con la renovada visión de la historiografia renacentista: la cronología (en cuanto a la estructura compositiva), el estilo plano sin pretensiones literarias (en cuanto a la expresión), el universalismo espacial, temporal y temático (en cuanto al contenido) y el providencialismo (en cuanto a la filosofia - cristiana - que alienta estas obras).

${ }^{39}$ E. Fueter (1953), p. 28. Al mismo tiempo, se aprecia en estos primeros autores cierto regusto evemerista que, contrariamente a lo que hace Livio al principio de su $A b$ urbe 


\section{LA HISTORIA COMO PROPAGANDA.}

La ejemplaridad va unida a la condición propagandística y nacionalista de la historia. Los modelos de conducta, llevados al terreno subjetivo que el autor siempre imprime a su obra, nos conducen a una visión publicista de la propia historia: los historiadores oficiales estaban obligados a dar pública información de unas acciones dignas de recuerdo, y en un lenguaje conveniente a los propios hechos narrados. Como dice Tate, "la emoción del narrador es un elemento inseparable de lo narrado,40. La ejemplaridad del relato presupone que lo narrado es verdad, aunque no lo sea: se trata de la vieja disyuntiva entre historia pragmática o panegírica, entre el Cicerón del De inventione o el De oratore y el de la Carta a Luceyo. De ahí que los gobernantes italianos sintieran una abierta simpatía hacia el género historiográfico, al que veían como una forma segura y honrosa de adquirir la inmortalidad: "Los señores buscan afanosamente a escritores que eternicen su nombre y su gesta, monumentos que los salven del inexorable fin" ${ }^{21}$. Los poderosos se convierten en mecenas, patrocinando las artes que embellecerán las ciudades con edificios y monumentos, creando bibliotecas, protegiendo a los hombres de letras e incluso convirtiéndose ellos mismos en intelectuales diletantes.

Del mismo modo que las estatuas o las pinturas, prolifera la historia como forma de perpetuación en el tiempo, y lo más importante, en lengua latina, ya que ésta era el vehículo de expresión comprensible por toda la Europa culta. $\mathrm{Al}$ mismo tiempo se estimula, desde las más altas instancias de poder, la traducción latina de obras históricas escritas en vernáculo. Es lo que sucede, por ejemplo, en Portugal, con la Crónica de D. Afonso Henriques, de Duarte Galvão, traducida al latín por el Infante D. Duarte, o en España con el propio Nebrija, cuyas dos obras históricas, las Décadas y el De bello Navariensi son adaptaciones - o mejor dicho, traducciones - de la Crónica de Pérez del Pulgar y de la Conquista del Reyno de Navarra de Luis Correa, respectivamente.

Así pues, la Europa culta se sirvió la historia para engrandecer con su ropaje retórico los hechos pretéritos de cada nación o de cada familia real, y exportarlos al resto del mundo ${ }^{42}$. La historia adquiere así una decidida

condita, desecha cualquier atisbo de mitología y milagrería poco creíbles para quien compone verdadera historia.

${ }^{40}$ R. B. TATE (1994), p. 19.

${ }^{41}$ E. GARIN (1986), p. 68.

${ }^{42}$ Obviamente, estas obras también se componían en lengua vernácula, aunque su difusión, lógicamente, era menor, ya que se limitaba al propio ámbito nacional. Sirva como ejemplo, en el caso de España, la Guerra de Granada de Diego Hurtado de Mendoza, que tuvo que competir con otras obras que trataban el mismo episodio de la revuelta morisca en 
vocación propagandística, visible en una mayor preocupación estética y retórica en la narración de los hechos, pero también en un deseo por persuadir al lector para que tome partido por la opción deseada; igual que Cicerón pide a Luceyo elaborar una monografia laudatoria de su consulado, en el período renacentista el relato histórico se reviste de un mayor ornato con el fin de glorificar a unos personajes y acciones en detrimento de otros: no será un relato de la totalidad de los hechos, sino de los más destacables, procediendo por auxesis. Esta preferencia por la narración de unos determinados hechos y el consiguiente silenciamiento de otros constituye, para los grandes estudiosos del Renacimiento, una de las objeciones contra la Historiografia latina de este período, por cuanto se resiente la veritas ${ }^{43}$.

Este "ardor propagandista", como lo llama Tate, "forma parte integrante del programa humanista que fue modelado no sólo por bien sabidos ideales culturales, sino también por los fines políticos de las ciudades-estados italianas" ${ }^{44}$. En efecto, no es casualidad que surjan en Italia historiadores oficiales como Bartolomé Facio, Antonio Beccadelli, "el Panormita" o Lorenzo Valla, que escriben historias vinculadas a la corte de Alfonso el Magnánimo, en las que el rey aparece como un nuevo emperador romano, hábil estratega, aficionado a las letras y querido por todos. Como señala Tate, la historiografía del reinado de Alfonso V es "la transposición de la era imperial a su propio tiempo" ${ }^{\text {, }}$, de la misma manera que otros historiadores tratan de plasmar en sus obras el ambiente y los ideales republicanos romanos de la ciudad-estado donde desarrollan su labor intelectual y de la que son cronistas oficiales. Es el caso de las historias de Florencia de Poggio Bracciolini o Leonardo Bruni, o Pietro Bembo y su Historia de Venecia ${ }^{46}$. En todas estas obras se atisba cierta

Granada, como la Historia del Rebelión y castigo de los moriscos del Reino de Granada) de Luis del Mármol Carvajal, o la segunda parte de las Guerras civiles de Granada, de Ginés Pérez de Hita. En Italia, y más concretamente en la "floreciente Florencia", surgen obras de título similar, que bucean en el glorioso pasado de la ciudad toscana para proclamar su esplendor presente, como las Istorie Fiorentine de Maquiavelo, las Storie Fiorentine de G. Cavalcanti, la Istoria di Firenze dall'anno 1380 all'anno 1405, de G. Dati o las Storie Fiorentine de Guicciardini.

${ }^{43}$ Así piensan, entre otros, FUETER (1953) o BURCKHARDT (1971).

${ }^{44}$ Cf. TATE (1970), p. 184.

${ }^{45}$ Cf. TATE (1970), p. 290 . De la misma manera que estos autores buscan retratar a Alfonso como el nuevo Julio César, otros historiadores como Margarit, Marineo Sículo o Nebrija hacen lo propio con los Reyes Católicos, paradigma de buenos gobernantes defensores de la fe cristiana frente a la amenaza de otras religiones.

${ }^{46}$ P. BracciolinI, Historiae Florentinae libri VIII (1450-1454); L. BRUNI, Historiae Florentini populi (1492); P. BEMBO, Rerum Venetarum historiae libri XII, 1487-1513 (1551). 
conciencia generalizada del concepto "patria", algo que Fueter denomina "historia publicista" y que procede de la escuela florentina fundada por el propio Bruni ${ }^{47}$ a partir de las enseñanzas de su maestro, el secretario Colluccio Salutati. Y es que, como indica $\mathrm{Garin}^{48}$, la historiografia renacentista nace en las ciudades-estado italianas, en un momento de crisis de valores republicanos que llevan a la implantación de nuevas formas de orden monárquico necesitadas de justificación histórica.

En el ámbito peninsular, en un momento de exaltación nacional y fervor religioso como son los últimos años del siglo $\mathrm{XV}$, surgen en España nombres como Nebrija, quien al amparo de los Reyes Católicos pregona la grandeza de España desde su labor de gramático (es autor de la primera gramática castellana) e historiador ${ }^{49}$. Pero el de Lebrija tendrá un duro competidor en la figura del siciliano Lucio Marineo, que escribe el De Grammatices institutionibus libellus brevis et perutilis ${ }^{50}$ como respuesta a las Introductiones Latinae de Nebrija, y una serie de obras históricas ${ }^{51}$ de marcado carácter panegírico hacia su país de adopción. Las disputas entre ambos por el codiciado cargo de cronista oficial de los Reyes Católicos ${ }^{52}$, así como por la implantación de sus respectivos métodos para la enseñanza del latín, han llenado y seguirán llenando páginas entre los estudiosos de la época, lo que da una idea del papel que desempeñan tanto la lengua "compañera del Imperio", como la historia, divulgadora de "hazañas" patrióticas y cristianas frente a las críticas de ciertos eruditos europeos, fundamentalmente italianos, que, con sus pretensiones de superioridad, habian denunciado "la barbarie y falta de madurez" hispanas ${ }^{53}$. Este nacionalismo a ultranza lleva a Nebrija a proclamar

47 J. BURCKHARDT (1971), p. 57 considera a Florencia como "el primer Estado moderno del mundo (...) la patria de la Historia en el nuevo sentido".

${ }^{48}$ E. GARIN (1976), pp. 19-33 y (1983), pp. 140 ss.

${ }^{49}$ No obstante, como señala R. B. TATE (1970), p. 184, "el interés de Nebrija por la historiografia fue únicamente secundario, originándose en sus trabajos editoriales, en su exégesis bíblica y en la acumulación de datos para sus gramáticas y léxicos". De hecho, sus obras históricas, por lo demás inacabadas, se publicaron póstumamente, y ello a pesar de su status de cronista regio.

${ }^{50}$ Publicada en Sevilla, en 1501. Conoció una segunda versión, la Grammatica brevis ac perutilis, publicada en Alcalá de Henares, en 1532.

${ }^{51}$ De laudibus Hispaniae libri VII (1504); De Aragoniae Regibus et eorum rebus gestis libri V (1509); De rebus Hispaniae memorabilibus Libri XXV (1530).

${ }^{52}$ El título de cronista oficial suscitaba envidias y rivalidades, no sólo entre los mismos humanistas, sino en general en toda la Corte, porque "precisamente su posición privilegiada le confería una debilidad cierta entre la maledicencia interesada de los cortesanos" (B. CUART MONER, 1994, p. 41).

${ }^{53}$ Son palabras de R. B. TATE (1970), p. 24. Entre estos intelectuales se encontraba, por ejemplo, Guicciardini. En cualquier caso, resulta curioso que algunos de estos 
la conveniencia de que sea un español quien escriba la historia de España, en clara alusión al origen siciliano de su rival, Marineo Sículo, e impulsará la edición de Sancho de Nebrija de las obras históricas de su padre, conjuntamente con otras en que se ensalza la grandeza de España, como son el Paralipomenon de Juan Margarit, el Cronicon de Jiménez de Rada o la Anacephalaeosis de Alfonso de Cartagena.

En Portugal, sobre todo a partir de 1530 , las conquistas de ultramar suscitaron un sentimiento nacionalista que vino acompañado de una política cultural programada por el propio monarca Juan III, que de una manera similar a Augusto en Roma, supo atraer a Portugal a los más brillantes humanistas extranjeros y portugueses "extranjerizados", maestros consagrados en el continente $^{54}$, como Damião de Góis, que en su Hispania sale al paso de las falsas acusaciones que el alemán Sebastián Münster lanza contra las toscas costumbres hispanas y su proverbial atraso en todos los órdenes. André de Resende recopila en su De antiquitatibus Lusitaniae el ancestral origen de Portugal, recopilando una gran cantidad de datos arqueológicos, históricos y culturales. En esta línea se mueven también humanistas como Diogo de Teive, autor de un Commentarius de rebus a Lusitanis in India apud Dium gestis (1548), que se inserta en la moda de las monografías que, a la manera de las modernas crónicas periodísticas, narran las campañas portuguesas en $\mathrm{Asia}^{55}$. En esta línea se hallan los Commentarii rerum gestarum in India citra Gangen a Lusitanis, anno 1538 (1539) y el De bello Cambaico ultimo commentarii tres (1549), ambas de Damião de Góis, o el Epitome rerum gestarum in India a Lusitanis, anno superiori (1531), de André de Resende. Es sintomático que todas estas obras se publiquen en Lovaina - lo que denota su pretensión propagandística -, que aparezcan de forma casi simultánea a los hechos (bello ultimo, anno superiori), y que se trate de hazañas portuguesas (a Lusitanis) en lugares remotos, ganados para la Cristiandad. No conviene olvidar que el fuerte sentimiento nacionalista de españoles o portugueses cuenta con un componente religioso casi de cruzada. De hecho, la comparación de las hazañas hispanas con las de griegos y romanos se convierte en un tópos literario que responde al

defensores de la riqueza cultural ibérica fueran, precisamente, italianos como Annio de Viterbo o Lucio Marineo Sículo.

${ }^{54}$ Otras acciones del rey portugués fueron el traslado de la Universidad a Coimbra o la fundación del Colegio das Artes, también en la ciudad del Mondego, creando así un verdadero foco de cultura que algún estudioso llamó "la primavera de Coimbra".

${ }^{55}$ Un similar aliento respira el De Asia de Eneas Silvio Piccolomini, en el que las enseñanzas morales y políticas presentes en la historia de otros autores dan paso a un afán meramente geográfico, descriptivo y divulgativo: lo que busca, sin más, es dar a conocer la geografia de este continente desconocido para el gran público. 
sentimiento de superioridad que deriva de su labor evangelizadora, de propagación de la $\mathrm{fe}^{56}$.

La historiografia, ya fuese en latín o en vernáculo ${ }^{57}$, atrajo el interés de los poderosos, que la sintieron como una herramienta utilísima para legitimar la expansión hacia nuevos territorios, la aparición de nuevas dinastías reales o de clases sociales emergentes ${ }^{58}$. Necesariamente, este tipo de relato "exaltado" se resiente de la veritas histórica, acercando la narración a otros géneros más "retóricos" como pueden ser el panegírico, siguiendo la senda marcada por Plinio, el Joven, o la poesía épica de tema histórico en que las afectadas convenciones del género están reñidas con el freno que la propia realidad de los hechos impone a la narración: cuanto más se exageren los hechos, tanto más inestable se mantendrá la credibilidad del mismo. Como señala López Moreda a propósito de las monarquías española y portuguesa, "en la anhelada y necesaria simbiosis de cristianismo y paganismo, que es una de las múltiples aportaciones renacentistas para salvaguardar la fe, a la vez que mantener la tradición clásica incorporada y revalorizada desde Petrarca, la referencia al mundo pagano fue constante, especialmente en pro de la necesidad de sustentar y patrocinar hombres de letras al servicio del Estado: 'Siempre la lengua fue compañera del Imperio', proclamaría Nebrija. De esta manera, como había ocurrido en tiempos del Imperio Romano, volvían a maridarse intereses literarios e intereses políticos, o, si se prefiere, para ser más explícitos, las monarquías europeas, especialmente la española y la portuguesa, se sirvieron de los hombres de letras para justificar su política expansionista y comercial a costa de moros primero y turcos después. Con la propagación de la fe como pretexto y los intereses comerciales como fin, las naciones europeas basan su ideología imperialista en la tradición cultural heredada del mundo clásico"59.

Pero ello no es sólo aplicable al ámbito hispano, ya que, como prosigue el mismo autor un poco más adelante, "el contexto literario conexo al político es

${ }^{56}$ Cf. N. N. CASTRO SOARES (2002), pp. 26: "O paralelismo com os valores e os heróis paradigmáticos da Antiguidade se torna um verdadeiro tópos no nosso humanismo, tanto nas obras em prosa como na poesia".

${ }^{57}$ Cf. R. B. TATE (1970), p. 281: "Nunca antes había atraído tanto la atención de nobles, clero y clase letrada la historiografia en latín y lengua vernácula".

${ }^{58}$ Una consecuencia de esto mismo es la creación de archivos reales en que se hace acopio de multitud de datos históricos, la proliferación de bibliotecas capitulares o nobiliarias o el nombramiento de archiveros encargados de conservar y ampliar esos registros; surge también la figura de cronista real que, a la manera de un moderno Homero o de un Virgilio, ensalce las hazañas o el abolengo de su protector, sea este un rey, un noble, una ciudad o toda una nación.

${ }^{59}$ S. LÓPEZ MOREDA (2004), p. 640. 
evidente; como había ocurrido en la antigua Roma a propósito de la relación entre letras y poder, ahora los humanistas de más prestigio sirven y se sirven de la corona, ocupan cargos administrativos de gran relevancia, se erigen en portavoces de los intereses reales y se disputan, a veces de manera escandalosa, el favor del príncipe, persiguiendo, entre otros fines, convertirse en los historiadores y cronistas oficiales" $"$. Esto último recuerda las desavenencias entre humanistas por erigirse en cronistas oficiales y ganarse así la gloria de cantar la grandeza de las distintas cortes europeas: buena muestra son Nebrija y Marineo Sículo en España, Valla, Facio y el Panormita en la corte napolitana de Alfonso el Magnánimo, o Cataldo Parisio en Portugal, quien, como su amigo Marineo en España, tuvo que hacer frente a voces nacionalistas que se oponían a que un extranjero cantase las hazañas portuguesas. Esta historia de exaltación nacional de la que venimos hablando acerca el género a la epopeya, a la manera de Livio, cuya introspección en el pasado de Roma no tiene otra razón que enaltecer su grandeza presente. En este sentido, no es extraño que los subgéneros historiográficos que gozan de mayor éxito en esta época sean aquéllos que denoten una evidente finalidad pragmática al tiempo que propagandística, como la biografia ${ }^{61}$, la monografia, las descripciones e historias de ciudades o la historia general y "total" de un pueblo, subgéneros todos que cuentan con modelos establecidos desde la Antigüedad. Así, las monografías de Salustio, los commentarii de César, la descripción de los germanos de Tácito, las biografias de Nepote o Suetonio, o el Panegírico a Trajano de Plinio afloran como modelos para otras tantas historias compuestas mil quinientos años después, todavía en lengua latina, y con una finalidad similar si no equivalente.

Al mismo tiempo, "bajo la influencia de compilaciones tales como la de Valerio Máximo, los imperativos éticos comienzan a derivarse no de los héroes-modelo de la alta Edad Media, sino de las acciones de Escipión, Quinto Metelo, Mucio Escévola y Bruto, cuyo sentido del deber no proviene, ni mucho menos, de la búsqueda de su prosperidad personal" ${ }^{\text {"62 }}$. Estas biografías, que muchas veces obedecen al encargo de algún familiar o adepto del biografiado, encierran un tono laudatorio del personaje en cuestión, cuyas

${ }_{60}^{60}$ S. LÓPEZ MOREDA (2004), p. 641.

61 No prolifera, en cambio, la autobiografia, aunque podemos contar, en el Renacimiento italiano, con algunas muestras, como la Vita del escultor Benvenuto Cellini (no publicada hasta 1728), el De propria vita Liber del médico Girolamo Cardano o los Pii II Commentarii rerum memorabilium quae temporibus suis contigerunt, de Eneas Silvio Piccolomini, el papa Pío II.

${ }^{62}$ Cf. R. B. TATE (1970), p. 286. 
características físicas, morales y sociales se pretende rescatar para siempre del olvido: basta citar la Historia de Fernando de Aragón, que Valla escribe por encargo del hijo de éste, Alfonso el Magnánimo, rey al que el humanista presta sus servicios en Nápoles y al que el Panormita dedica también su De dictis et factis Alphonsi regis. Burckhardt o Garin han llamado la atención sobre este desarrollo de la biografia en el Renacimiento italiano, atribuible a la importancia que cobran en este periodo las acciones singulares, frente a la época medieval, en que el individualismo quedaba diluido en lo general: "Más que el artista, lo que contaba era la obra", dice Garin ${ }^{63}$, y añade que, mediante el relato de estas acciones individuales, "el escenario del mundo se puebla con figuras poderosas que permanecen vivas para nosotros en las páginas de los historiadores". La historia así concebida se asienta sobre figuras heroicas cuya gloria es necesario referir para generaciones venideras; pero además, esta reflexión sobre el individuo como héroe o villano que con sus acciones influye en el devenir de los tiempos, imprime un tono introspectivo, de investigación anímica de los comportamientos, un elemento característico de Salustio, a la sazón uno de los historiadores más leídos, citados e imitados. Simultáneamente, destaca la monografia histórica de tono laudatorio, en la línea del propio Salustio o Tácito, pero cercana también a los commentarii de Julio César, que se centran en episodios evangelizadores y expansionistas, como es el caso de las crónicas ya citadas de Damião de Góis, André de Resende o Diogo de Teive sobre las campañas portuguesas en el sur de $\mathrm{Asia}^{64}$.

En el seno de las múltiples ciudades-estado italianas surgen igualmente historias y descripciones panegíricas de pueblos y ciudades, como las historias de Florencia de Poggio Bracciolini o Bruni, que justifican su rango en el esplendor y vetustez de esas ciudades-estado frente a otras, vinculando, de paso, sus orígenes al glorioso pasado de Roma, moda esta que de inmediato irradia a la Península, en forma de laudes urbium como la Olisiponis

${ }^{63}$ E. GARIN (1986), p. 229. Cf., sobre todo, el capitulo dedicado al "Desarrollo del individuo", en J. BURCKHARDT (1971), pp. 99-127.

${ }^{64}$ En estas monografias y en otras por el estilo, es común la descripción de costumbres y hábitos de estos pueblos recién evangelizados o desconocidos por el gran público, todo ello con el propósito de subrayar la importante labor que la nación colonizadora en cuestión desarrolla a favor de la Cristiandad. Cf. otras monografias de Góis, como la Fides, religio moresque Aethiopum o la Deploratio Lappianae gentis, en que se habla concretamente de etíopes y lapones. No es sino una prueba más del sentimiento de universalidad inherente al período renacentista y que adquiere en la historia (y más concretamente en la descripción de pueblos) un vehículo muy apropiado de expresión. Tampoco hay que olvidar el auge que toman en estos siglos los tratados de geografia, que se escriben normalmente para corregir, mejorar o completar los tratados clásicos y que se entienden también como medio de propaganda del impulso colonizador en lugares remotos. 
Descriptio de Góis. Y por extensión, de la urbs se pasa al país: en esta línea se mueven la Historia Anglica de Polidoro Virgilio, la Rerum Scoticarum Historia de George Buchanan, o el De antiquitatibus Lusitaniae de André de Resende.

Utilidad y propaganda, ejemplo para el futuro y divulgación de unos hechos son dos caras de la misma moneda: la historia se erige en modelo de virtudes que enseña a los políticos cómo actuar en sociedad, pero también inmortaliza los hechos gloriosos de una patria, casa real o personaje concreto. Como memoria escrita, la historia debe ser fruto de la eloquentia de esos oratores que son los historiadores, valiéndose de la universalidad de la lengua latina y respetando los modelos establecidos para el género desde la Antigüedad y renacidos a partir del siglo XV.

\section{BIBLIOGRAFÍA}

ARAGÜÉs AlDAZ, J., "El modelo de los dicta et facta memorabilia en la configuración de las colecciones de exempla renacentistas", Humanismo y Pervivencia del Mundo Clásico. Actas del I Simposio sobre Humanismo y Pervivencia del Mundo Clásico (Alcañiz, 813 mayo 1990), (J. Mª Maestre \& J. Pascual, coords.), vol. I, Cádiz, 1993, pp. 267-282.

BURCKHARDT, J., La cultura del Renacimiento en Italia. Barcelona, Iberia, 1971 (= Basel, 1860).

CASTRo SoAREs, N. N., "A historiografia do Renascimento em Portugal: Referentes estéticos e ideológicos humanistas", Aquém e além da Taprobana, Estudos Luso-Orientais à Memoria de Jean Aubin e Denys Lombard, Lisboa, Fund. Calouste Gulbenkian, 2002, pp. 15-37.

Cotroneo, G., I trattatisti dell'ars historica, Napoli, 1971.

CUART MONER, B., "La historiografia áulica en la primera mitad del siglo XVI: los cronistas del emperador", Antonio de Nebrija: Edad Media y Renacimiento (C. Codoñer \& J. A. González Iglesias, eds.), Salamanca, 1994, pp. 39-58.

FERGUSON, W. K., Il Rinascimento nella critica storica, Bologna, 1969.

FonTÁN, A., Humanismo romano, Barcelona, Planeta, 1974.

FUETER, E., Historia de la historiografia moderna, Buenos Aires, 1953 (= Paris, 1914).

GALÁn SÁNChEZ, P. J., El género historiográfico de la chronica. Las crónicas hispanas de época visigoda, Cáceres, 1994.

Garin, E., La cultura del Rinascimento, Bari, Laterza, 1976.

GARIN, E., El Renacimiento italiano, Barcelona, Ariel, 1986 (= Bologna, 1980). 
HiNOJO ANDRÉS, G., "Nebrija y la historiografia renacentista: La Fortuna", Antonio de Nebrija: Edad Media y Renacimiento (C. Codoñer \& J. A. González Iglesias, eds.), Salamanca, Universidad, 1994, pp. 29-38.

LÓPEZ MOREDA, S., "El modelo de princeps en la obra histórica de Lorenzo Valla", Humanitas 56 (2004), pp. 401-423.

TATE, R. B., Ensayos sobre la Historiografia peninsular del Siglo XV, Madrid, 1970.

TATE, R. B., "La historiografia del reinado de los Reyes Católicos", Antonio de Nebrija: Edad Media y Renacimiento (C. Codoñer \& J. A. González Iglesias, eds.), Salamanca, Universidad, 1994, pp. 17-28. 